\section{A relação entre o nível de Empreendedorismo (TEG) e os aspectos sociodemográficos dos Taxistas cooperados da cidade de Santo André/São Paulo, Brasil Santo Andrélsăo Paulo, Brasil}

\section{The relationship between the level of entrepreneurship (TEG) and socio / demographic aspects of cooperative Taxi drivers in the city of Santo André / São Paulo, Brazil}

\author{
Alessandro Marco Rosini ${ }^{1}$ \\ Luís Flávio Chaves Anunciação ${ }^{2}$ \\ Marcia Welita da Silva ${ }^{3}$ \\ Sandro Braz da Silva ${ }^{4}$ \\ Sergio Roberto Silva ${ }^{5}$ \\ Silvia Regina Guberovic ${ }^{6}$
}

\begin{abstract}
Resumo
O objetivo deste trabalho foi identificar o nível de empreendedorismo em 147 taxistas de Santo André/SP, bem como averiguá-lo em associação aos aspectos sociodemográficos. Utilizou-se a metodologia quantitativa e para avaliar o grau de empreendedorismo elegeu-se o instrumento TEG (Tendência Empreendedora Geral) de Caird (1991). Os resultados indicaram uma população majoritariamente masculina $(89 \%)$, casada $(58,5 \%)$ e com o ensino médio (colegial) concluído $(57,8 \%)$. Quanto ao grau de empreendedorismo, em nenhum dos constructos analisados os taxistas obtiveram a média para serem classificados empreendedores. Revelou-se que a escolaridade possui efeito significativo à TEG $(\mathrm{F}(3,147)=$ $3,747, \mathrm{p}<.05)$ : quanto mais anos de estudo, tanto maior é o nível da TEG. Em outra direção, o tempo de empresa (F $(30,147)=30,274, \mathrm{p}<.05)$.
\end{abstract}

Palavras-chave: Empreendedorismo. TEG. Taxistas. Administração.

\begin{abstract}
The goal of this study was to identify the level of entrepreneurship of taxi drivers in Santo André/São Paulo and analyze its correlates. This paper works on a quantitative methodology and involved 147 taxi drivers of a cooperative. To assess this latent trace, we used the General measure of Enterprising Tendency (GET) from Caird (1991). The results show a sample formed mostly by married male with high school. The tendency of entrepreneurship in all constructs was below of the expected average for the cut-off point for entrepreneurs. Years of schooling had a positive significant effect to GET $(\mathrm{F}(3,147)=3,747, \mathrm{p}<.05)$, but the length of service in the company was negatively correlated to some constructs in GET $(\mathrm{F}(30,147)=30,274, \mathrm{p}<.05)$.
\end{abstract}

Key-words: Entrepreneurship. General measure of Enterprising Tendency. Taxi drivers. Manager.

\footnotetext{
${ }^{1}$ Pós-Doutor em Administração de Empresas pela FEA USP. FMU- Faculdades Metropolitanas Unidas -SP. E-mail: alessandro.rosini@fmu.br

${ }^{2}$ Doutorando na PUC do RJ. PUC-Rio- Departamento de Psicologia. E-mail: luisfca@gmail.com

${ }^{3}$ Mestranda Profissional em Administração de Empresas com linha de pesquisa em Governança Corporativa - FMUFaculdades Metropolitanas Unidas -SP e UNINOVE-Universidade Nove de Julho-SP. E-mail: mwelita@hotmail.com ${ }^{4}$ Doutorando em Administração de Empresas com foco em Finanças Corporativas, no Mackenzie. UPM-Universidade Presbiteriana Mackenzie E-mail: sergioroberto@auditaconsultoria.com.br

${ }^{5}$ Mestre em Ciências Contábeis pela FECAP-SP. FGV-EAESP-Fundação Getúlio Vargas. E-mail: sergioroberto@auditaconsultoria.com.br

${ }^{6}$ Mestranda em Administração de Empresas curso Profissional em Governança Corporativa. FMU- Faculdades Metropolitanas Unidas e Faculdade ENIAC E-mail: sguberovic@hotmail.com
}

Artigo recebido em: 19 de março de 201. Artigo aceito em 06 de março de 2017. 


\section{INTRODUÇÃO}

A atualidade vivida é baseada no processo que envolve o conhecimento e a informação. Os produtos da TIC - Tecnologias de Informação e Comunicação alimentam esse processo, que por meio de produtos e serviços como os aplicativos, cada vez mais fazem parte do dia a dia das pessoas. Um desses softwares é o aplicativo UBER (2015).

Esse aplicativo interliga pessoas que necessitam de um transporte a outras pessoas comuns que estão disponíveis a usar seu carro pessoal para efetuar esse transporte. Nesse conceito, qualquer motorista (devidamente habilitado e aceito pelo UBER) pode oferecer uma "carona" e ganhar um valor por esse serviço. O aplicativo baseia-se na filosofia de aumentar a mobilidade dentro das cidades. Ao mesmo tempo, proporciona uma remuneração "extra" aos motoristas que, muitas vezes, vão e vêm com seus carros vazios. Compartilhamento de serviços aumenta a mobilidade e melhor aproveita os recursos naturais (OLHAR DIGITAL, 2015; G1, 2015).

Esse aplicativo proporciona um aumento da concorrência entre os profissionais de transporte denominado "taxistas". A pesquisa da CNT - Confederação Nacional de Transportes (BRASIL - CNT, 2016) destaca que 94,9\% dos taxistas registram queda na demanda dos serviços de táxi.

Dessa forma, essa classe profissional precisa mudar a sua estratégia a fim de permanecer em sua profissão. A mudança de estratégia consiste em rever o atual cenário e projetar as mudanças necessárias para manter o status quo. Portanto, avaliar o grau de empreendedorismo desses profissionais talvez possa ser uma ferramenta para a equalização desse novo cenário empresarial.

O empreendedorismo é um assunto recente em todas as sociedades, principalmente como alternativa às crises econômicas. Várias universidades incorporaram em suas grades disciplinas que buscam desenvolver competências empreendedoras em seus formandos na busca de uma maior empregabilidade.

Nesse cenário, os autores visaram responder à pergunta "Qual o nível de empreendedorismo dos taxistas avaliados?" Como objetivo geral, buscou-se identificar o grau de empreendedorismo dos taxistas. Como população, escolheu-se uma cooperativa de taxistas da cidade de Santo André. Como instrumento de mensuração, elegeu-se o TEG - Tendência Geral empreendedora de Caird (1991). Secundariamente, 
buscou-se avaliar as características sociodemográficas relacionadas a esse nível de empreendedorismo.

Como parte da pesquisa lançou-se as seguintes hipóteses:

H1 - Os taxistas possuem grau de empreendedorismo acima da média.

H2 - Quanto maior o nível de educação formal do taxista, tanto maior é o seu grau de empreendedorismo.

H3 - Quanto maior o tempo na profissão, tanto maior é o grau do empreendedorismo.

Acredita-se que esta pesquisa possa contribuir para entender (grau de empreendedorismo entre os taxistas) que ainda há poucos estudos publicados. Indiretamente, esse trabalho apresenta resultados que podem ser propulsores para novos programas de capacitação às entidades que apoiam esses atores sociais. Academicamente, a reunião das referências pode sugerir novas contribuições nessa temática.

O artigo está dividido em cinco partes: introdução, revisão da literatura, metodologia da pesquisa, discussão dos resultados e considerações finais.

\section{REFERENCIAL TEÓRICO}

O proposto da pesquisa revela quatro pontos importantes no estudo: os taxistas, o empreendedorismo, o método de avaliação do empreendedorismo e, por fim, o ambiente dos taxistas estudados: as cooperativas. É nesses temas que está dividido o referencial teórico deste estudo.

\subsection{Condições de trabalho dos taxistas: características}

O serviço de táxi é conhecido mundialmente. Suas formas de apresentação variam de cor, forma e idioma. Porém, todos eles possuem a mesma filosofia: transportar.

O táxi é a modalidade de transporte individual pela qual o passageiro aloca o veículo, seu motorista e determina a rota a ser percorrida. O motorista do veículo é chamado de "taxista" e já foi tema de um filme chamado "Taxi Driver", do diretor Martin Scorsese (HERO, 2014).

A Confederação Nacional de Transportes (BRASIL - CNT,2016) fez um estudo caracterizando esses profissionais. Em seus resultados, destacam que 97,3\% são do sexo masculino. O grau de escolaridade mais frequente é o ensino médio concluído, com 
$45,7 \%$ e no ensino fundamental concluído - antigo ginásio com $14,2 \%$. O estado civil que mais se destaca é o casado, com $68 \%$ da população entrevistada.

Para o exercício do serviço de taxista o interessado deve passar por um programa de formação ditado pelo Conselho Nacional de Trânsito (CONTRAN) (BRASILDENATRAN-Portaria 168/2004) e uma autorização do governo municipal (BRASIL lei 12.587/2012) conhecida como "licença" (Dias, 2007).

Nóbrega (2008) destaca que a escolha pela profissão é uma segunda opção. Essa escolha é fruto do processo de reestruturação das organizações (downsizing) que demitem os profissionais e que, sem alternativa, acabam escolhendo o táxi como meio de sobrevivência.

O Estudo da Confederação Nacional dos Transportes (2016) revela que 28\% dos taxistas possuem menos de cinco anos na profissão. Vinte e três por cento dos taxistas estão entre cinco e dez anos na profissão. Apenas 10,6\% possuem mais de 31 anos de profissão. O estudo indagou se antes de ser taxista possuía profissão. Dos entrevistados, 88,8\% afirmaram que sim. Esses indícios ratificam o estudo de Nóbrega (2008). As atividades antes exercidas concentram-se no comércio, com $28 \%$, e em outras áreas do transporte (motoristas de ônibus, motoristas em empresas, por exemplo), com 25,5\%, a opção anterior "indústria" aparece em $22,6 \%$ dos casos estudados.

A pesquisa (BRASIL - CNT, 2016) revela ainda que a opção por taxista melhorou os rendimentos financeiros em 51,2\% dos casos e em 30,09\% dos casos permaneceu a mesma. Somente em 16,9 \% a situação piorou. Dessa forma, é possível inferir que a opção profissional de taxista melhorou a condição desses trabalhadores.

Frente a essa situação, há, ainda, o estudo de Veloso, Oliveira Filho, Medeiros (2009), que revela taxistas desiludidos com a profissão, concebendo-a como decadente. No entanto, sabem que é essa profissão que lhes garante a sobrevivência numa sociedade "difícil e instável".

Os entrevistados na pesquisa de Silva Neto (2011) e Nascimento (2010) retratam a si mesmos e ao grupo ao qual pertencem como trabalhadores que lutam pela sobrevivência em meio à violência da profissão. Os resultados da pesquisa CNT Confederação Nacional dos Transportes (2016) relatam que 74,6\% entendem que o ponto negativo principal da profissão é a insegurança/violência.

Rosa (2012) identifica a percepção de "sobrevivência" pelos taxistas ao afirmar: “(...) mesmo com o medo da criminalidade e com as dimensões que agravam seus 
problemas de saúde, a melhor remuneração torna-se praticamente a única justificativa para tal preferência [a de taxista]".

Em se tratando de remuneração, os estudos da Confederação Nacional dos Transportes (2016) apontam um ganho médio diário de $\mathrm{R} \$ 224,69$. A remuneração média do grupo foi de $\mathrm{R} \$ 2.675,42$. No entanto, a faixa $\mathrm{R} \$ 1.001,01$ a $\mathrm{R} \$ 2.000,00$ representa $32 \%$ da população. A faixa seguinte dos taxistas $\mathrm{R} \$ 2.001,01$ a $\mathrm{R} \$ 3.000,00$, representa $26.04 \%$ da população.

Esta pesquisa revela que em média esse taxista possui dois dependentes $(29,3 \%)$, seguido dos taxistas que possuem três dependentes, com 26,3\%. Quando indagados sobre moradia, $67,1 \%$ indicam que possuem casa própria quitada, seguida de $22,2 \%$, que alugam a sua residência.

A pesquisa (BRASIL - CNT,2016) revela que 22,9\% dos taxistas possuem automóveis fabricados no ano de 2014, e 22,5\% possuem automóveis fabricados no ano de 2015.

Casteli (2006) destaca a habilidade de servir como elementar na profissão. Além deste, Di Muro Perez (2001) cita o compromisso com a segurança e o conforto de seus clientes. De todos esses, a habilidade comunicacional em idioma próprio e no estrangeiro é relevante.

Gany et al. (2012) identificam que nas grandes metrópoles, de cada dez taxistas, seis relatam jornada de trabalho maior ou igual a doze horas diárias. Esse fato aumenta o risco de pressão alta (VIEIRA, 2009). Barros et al. (2013) apontam alto grau de consumo de bebidas alcoólicas, alto risco de obesidade e tabagismo (LOPES E TOIMIL, 2011), consumo de bebidas energéticas e alto risco de desenvolver patologias na coluna, por exemplo hérnia de disco (Chanffin, 2005). No entanto, o fator estresse é institucionalizado entre os profissionais, conforme estudo de Braga e Zille (2015).

\subsection{Empreendedorismo}

Em relação aos estudos sobre empreendedorismo, economistas e comportamentalistas têm se destacado no desenvolvimento de estudos relativos ao tema.

Serafim e Feuerschutte (2015) relatam as ideias de Schumpeter (1883-1950) em relação ao empreendedorismo como "um agente que, ao promover novas combinações das dimensões de produção, promove desenvolvimento econômico". 
Nesse cenário econômico alterado, principalmente pelos altos níveis de desemprego, o empreendedorismo é visto como uma alternativa real de sobrevivência e retorno ao trabalho (ESTHER, 2014). Gestores públicos passaram a incentivar o empreendedorismo como solução ao cenário social e econômico no Brasil e na Europa também (Almeida, Santos, Albuquerque, 2013; Nobre, 2012).

Cunha (2007) caracteriza essa alternativa de política pública como "salvacionista", utilizando a estratégia do tipo "patrões de si mesmo" como mecanismo de persuasão entre os desempregados/empregados. Barros e Pereira (2008) concluíram que o empreendedorismo associou-se à redução do desemprego, mas não se associou ao crescimento econômico. Tal conclusão deu-se pela análise da taxa de empreendedorismo (expresso pela abertura de novas empresas) e o seu impacto no PIB.

GEM (2014) aponta que a proporção de empreendedores por oportunidade em relação à TEA - Taxa de Empreendedores Iniciais - é de 2,4 por oportunidade. Ou seja, tem-se mais empreendedores por oportunidade do que por necessidade. Isso representa, para o Brasil, 70,6\% das novas empresas abertas. Destaca, ainda, que o masculino encontra-se em $51,7 \%$, seguido do feminino, com $48,2 \%$. Por fim, o dado estado civil é destacado pelo mesmo autor, com predominância de casados $(47,8 \%)$, seguido dos solteiros $(27,7 \%)$.

\subsection{Tendência Geral Empreendedora (TEG)}

O foco dos estudos comportamentalistas sobre empreendedorismo está no sujeito empreendedor. Esses estudos visam observar, descrever e propor uma mensuração das características do sujeito relacionado ao empreendedorismo. Esses estudos tiveram como destaque David McClelland, que passou a buscar uma definição de empreendedor a partir do estudo de seu comportamento e não do seu "produto" como foi com os economistas.

Nessa abordagem, o modelo de Caird (1991) é desenvolvido com foco comportamentalista. Esse modelo é chamado de TEG - Tendência Geral Empreendedora. Modelo esse que tem sido utilizado na academia em diversas áreas, a saber: entre estudantes de Administração (Simão, 2012; Flores E Santos, 2014; Gaião, Lira, Queiroz, 2009; Pantzier, 1999 e Iizuka, Moraes, 2014); ocupações gerais (Souza, Silveira, Nascimento, Santo, 2014); estudantes da área da saúde (carreiro, Coutinho e Coutinho, 2010; carreiro, Coutinho, melo, 2010); profissionais gerentes (Russo e 
Sbragia, 2007; GUERBALI, OLIVEIRA, Silveira, 2013); professores (leal, 2011); estudantes de diversos cursos (Rosa, Rosa, Berto e Duarte, 2011; Vedoin, Garcia, 2010) estudantes de Ciências Contábeis (Niveiros, Almeida, Arenhardt, 2008) e estudantes de Engenharia (lira, lira morais, 2005; peloggia, 2001; araujo, dantas, 2009).

Esse modelo mensura o empreendedorismo em cinco dimensões. São elas: 1 necessidade de realização; 2 - necessidade de autonomia; 3 - tendência criativa; 4 disposição a riscos e 5 - impulso e determinação.

A necessidade de realização é destacada por Brancher, Oliveira e Roncon (2012), citando McClelland (1962), e apresentada na figura de uma pessoa que coloca à prova seus limites para realizar um bom trabalho. Esse tipo de pessoa procura mudanças em sua vida, coloca-se em situações competitivas e estabelece metas que, para si, são realistas e realizáveis. Segundo o referido estudo, essa dimensão é a primeira necessidade identificada entre os empreendedores bem-sucedidos. E, senão, a grande impulsionadora das pessoas na construção de um empreendimento.

Esse tipo de característica faz que a pessoa desenvolva uma visão de onde deseja chegar, além de autossuficiência e uma postura mais otimista, na maioria das vezes. Ainda se destacam a confiança em si mesmo, a persistência nos objetivos, o alto grau de energia para atingir e concluir seus objetivos (Russo e Sbragia, 2007).

Simões (2012) destaca que deficiências nesse constructo sugerem falta de ambição e descrença em relação à possibilidade de atingir o sucesso. De igual forma, preferência por estabilidade, cumprimento de ordens e realização de tarefas preestabelecidas são preteridas por esses índices abaixo da média.

A necessidade de autonomia/independência, segundo Simão (2012), é representada pela realização pessoal por intermédio de atividades pouco convencionais, na maioria das vezes um trabalho sozinho. Dessa forma, o empreendedor pode priorizar os seus objetivos pessoais (com foco na visão) e expressar suas decisões ao invés de receber ordens e não se prender às decisões do grupo.

Os dados da pesquisa CNT - Confederação Nacional dos Transportes (BRASIL CNT, 2016) revelam que o ponto positivo da profissão é autonomia para definir o horário de trabalho, com $62,3 \%$. Em segundo lugar, a possibilidade da profissão permitir o horário diversificado, com $40,7 \%$.

Já a tendência criativa, para Caird (1991), é manifestada pelas qualidades de inovação e imaginação. Geralmente, essas pessoas "sonham acordadas", projetando suas 
ideias. São, na maioria, curiosas e versáteis. São pessoas que sempre possuem várias ideias, gostam de novos desafios e utilizam muito a intuição. Para Dolabela (2006), essa é a dimensão mais importante em um empreendedor.

Dolabela (2008) destaca algumas deficiências nessa dimensão em estudo com brasileiros. Na maioria das vezes, os brasileiros preferem copiar negócios já existentes, ao invés de apresentar novos negócios (SimÕes, 2012, p. 105).

A disposição a riscos é refletida em características de tomada de decisão, mesmo quando se está com informações incompletas. Nesse caso, a avaliação de benefícios é importante para equilibrar o possível fracasso. Salim et al. (2004) destacam que essa é uma das características mais importantes.

O impulso e determinação estão relacionados à capacidade de ter iniciativa e buscar aproveitar as oportunidades de mercado. Dessa forma, esse empreendedor procura controlar o destino do seu próprio negócio (antipredestinação) com a autoconfiança equilibrando esforço e resultado. Essa característica não aceita o que se considera como predestinação (Ferreira, Aranha, 2008).

\subsection{Cooperativas de táxi}

Schmidt e Perius (2003, p. 63) definem as cooperativas como "associações autônomas de pessoas, unidas voluntariamente, para atender suas necessidades e aspirações econômicas, sociais e culturais comuns, através de uma empresa coletiva e democraticamente controlada", empresas cujo fim imediato é o atendimento das necessidades econômicas de seus usuários (CARDOSO, 2014).

São sociedades de pessoas, com forma e natureza jurídica próprias, de natureza civil, não sujeitas à falência, constituídas para prestar serviços aos associados, distinguindo-se das demais sociedades (BRASIL - Lei $\mathrm{n}^{\circ}$. 5.764/71).

Lins (2001) destaca que as cooperativas foram criadas ao longo da década de 1990, buscando flexibilização, redução de custos e desregulamentação das atividades. Nessa época, a sociedade já sentia os efeitos dos avanços na tecnologia e as novas formas de produção (DELFINO, Land, Silva, 2010, GAWLAK; RATZKE, 2001). Esses efeitos refletiram em crescentes índices de desemprego e em alguns casos a precariedade do trabalho.

Stefano, Zampier, Grzeszczeszyn (2006) enfatizam a participação dos cooperados na autogestão de seus atos. Os cooperados não somente assumem a 
administração coletiva, bem como, a responsabilidade pelo sucesso e pelo fracasso do esforço comum. A autogestão exige não somente um esforço físico, de presença na cooperativa ou na assembleia, mas, sobretudo, uma participação ativa e intelectual.

O Brasil possui 6.827 cooperativas, distribuídas em todos os Estados, com maior concentração nas regiões Sul e Sudeste do país (OCB, 2015). As cooperativas de transporte totalizam 1.228 em todo o Brasil. Estas geram 11.685 empregos diretos e um total de cooperados na ordem de 137.543 (OCB, 2015).

O estudo de Melgarejo-Molina, Vera-Colina, Mora-Riapira (2012) comparou as cooperativas a empresas com objetivo de lucro. Este estudo identificou que no caso das cooperativas o esforço do cooperado é maior e, por conseguinte, proporciona maior produtividade às cooperativas. $\mathrm{O}$ estudo aponta que as cooperativas tendem a proporcionar maior estabilidade entre os trabalhadores, fato esse que contribui para o aumento da produtividade. Com relação à taxa de sobrevivência (mortalidade), as cooperativas apresentam ligeira vantagem em relação às organizações. Por fim, os pesquisadores relatam que a questão da propriedade do capital interfere positivamente na produtividade desse tipo de organização.

No entanto, alguns pesquisadores não compartilham dessa opinião, ao opinarem que as cooperativas, em alguns casos, levam à degradação do emprego (Delfino, Land e Silva, 2010; Guarda Bassio, Amorin, Pereira, 2013; Miranda e Tinoco, 2002; Silva e Giesta, 2007). Bento, Trindade, Lima e Garcia (2013) apontam que, em alguns casos, funcionários subordinados são "disfarçados" de cooperado visando à sonegação dos custos trabalhistas. Fraude essa que prejudica os direitos do trabalhador.

\section{METODOLOGIA DA PESQUISA}

A tipificação (ou taxionomia) da pesquisa científica, segundo Teles (2001, p. 84), apresenta aspectos relacionados à condução da pesquisa que se expõe neste trabalho.

Com relação ao tipo de pesquisa, classifica-se como teórico-empírico. Para Demo (1985), esse tipo de pesquisa visa extrair parte de uma realidade (novos desafios tecnológicos dos taxistas) e busca referencial teórico capaz de explicar esse ponto estudado. Nesse cenário, a pesquisa também é aplicada a essa realidade. Na fase de revisão bibliográfica, não se encontrou estudo com esse mesmo propósito, nesse aspecto essa tentativa de sistematização classifica-se como exploratória. Como procedimento, a mesma é classificada como quantitativa, utilizando um instrumento de mensuração que 
envolve tratamento estatístico dos dados. A pesquisa também é interdisciplinar, envolvendo outros campos do saber como Administração, Psicologia, Antropologia e Sociologia. A fonte dos dados é primária e foi coletada uma única vez - Transversal segundo (Cooper, Schindler, 2003, p. 129) junto aos sujeitos (taxistas) no primeiro semestre de 2014. A relação direta entre a pesquisa e os pesquisadores é do tipo não participante; no aspecto da relação indireta, foi intermediada por uma consulta documental e bibliográfica.

\section{Participantes:}

A população da pesquisa é o profissional condutor de táxi cooperado. A amostra é do tipo não-probabilística (por conveniência). Nesse caso, escolheu-se a maior cooperativa de táxi da cidade de Santo André e, em seguida, os condutores foram convidados a participar. A quantidade total de associados era de 230. Considerando um nível de confiança desejado 95\%; erro máximo de 0,05 (alfa) e desvio-padrão de 0,5, chegou-se a uma amostra de 145 taxistas. Conseguiu-se, no entanto, entrevistar 147 taxistas. Nenhum formulário foi desprezado por falta de preenchimento.

\section{Procedimento:}

O plano de coleta dos dados envolveu o convite à direção da Cooperativa e, em seguida, um convite aos cooperados. Aos taxistas que aceitavam, era fornecido o Termo de Consentimento Livre e Esclarecido, com a ficha individual com as questões. Ao final era recolhida a ficha. Foram feitos cinco encontros com os taxistas, dada a rotatividade dos horários.

\section{Instrumento:}

O instrumento utilizado para a avaliação do empreendedorismo foi a TEG (CAIRD, 1991), um inventário psicométrico, composto por 54 itens dicotômicos que avaliam cinco constructos relacionados ao empreendedorismo. A saber: Tendência de assumir riscos, Tendência criativa, Necessidade de realização, Tendência de autonomia e Tendência à determinação. Existem evidências de sua validade psicométrica (CAIRD, 1991) e a tabela utilizada para pontos de corte foi baseada em Ferreira e Aranha (2008). 


\section{Análise estatística dos dados:}

O plano de análise dos dados teve esquema de fases sucessivas. No primeiro momento, as variáveis categóricas foram tratadas com frequências e porcentagens e, em seguida, calculou-se o valor do nível de empreendedorismo de cada participante considerando o manual do TEG (soma simples dos valores). Esse momento serviu para expor a amostra, descrever itens qualitativos e expor seus resultados acerca do empreendedorismo.

O segundo momento foi ancorado em técnicas de modelagem estatística. Assim, fez-se um Modelo Linear Generalizado, considerando uma ANOVA, para verificar a relação entre variáveis sociodemográficas (e.g., sexo e escolaridade), tendo o resultado do TEG como variável dependente (VD). Os testes post hoc desse momento foram eleitos a partir da análise da significância entre as variáveis ou suas interações, e optouse pelo método Bonferroni para maximizar o controle do erro do tipo 1, ou falso positivo. As médias das variáveis estatisticamente significativas foram descritas pela técnica de Duncan, uma vez que ela se destina à comparação e organização simples das médias consideradas estatisticamente diferentes.

O terceiro momento foi fundamentado nos indicadores a priori do instrumento em associação com os resultados obtidos pelos participantes. Assim, objetivou-se comparar e posicionar os participantes desta pesquisa à estrutura fatorial sugerida pelo instrumento, bem como, verificar seus resultados em face dos pontos de corte sugeridos pela autora do TEG. Para isso, calculou-se os itens relacionados às cinco dimensões do instrumento (e.g., tendência de assumir riscos, tendência criativa, necessidade de realização, tendência de autonomia e tendência à determinação). Além de comparar os resultados médios obtidos em cada dimensão utilizando um T de student, uma ANOVA foi feita. Dessa vez, as VD eram as dimensões do instrumento. As VIs foram as variáveis categóricas.

Trabalhou-se com o alfa em 0,05 e o software utilizado para essas análises foi o Statistical package for the social sciences (SPSS) em sua versão 22.

\section{RESULTADO DA PESQUISA E DISCUSSÃO}

A apresentação dos resultados inicia com dados sociodemográficos e de variáveis qualitativas. Em seguida, com a mensuração do grau de empreendedorismo e, ao fim, com a relação entre o empreendedorismo e possíveis variáveis preditoras. 


\subsection{Características sociodemográficas dos taxistas}

O gênero na pesquisa indica que dos 147 entrevistados, apenas 16 são mulheres, assim o percentual de mulheres fica em 10,9\%. Esse dado caracteriza a população como majoritariamente masculina. A comparação dos dados da pesquisa com os dados GEM (2014) mostra convergência dos dados. A Tabela 1 complementa esses dados. Esses mesmos dados convergem também com a pesquisa CNT-Confederação Nacional dos Transportes (2016), ao afirmar que mais de 97\% são do sexo masculino.

Tabela 1-Gênero entre os empreendedores brasileiros

\begin{tabular}{|c|c|c|c|c|}
\hline Dimensão & Item & $\begin{array}{c}\text { Resultados } \\
\text { da } \\
\text { pesquisa } \\
\end{array}$ & $\begin{array}{c}\text { Empreendedores } \\
\text { Estabelecidos } \\
\end{array}$ & $\begin{array}{c}\text { Dados do } \\
\text { GEM(2014) } \\
\text { em relação à } \\
\text { pesquisa }\end{array}$ \\
\hline \multirow{2}{*}{ Gênero } & Masculino & $89,10 \%$ & 54,9 & convergente \\
\hline & $\overline{\text { Feminino }}$ & $10,9 \%$ & 45,1 & convergente \\
\hline
\end{tabular}

Fonte: GEM (2014).

O estado civil dos participantes indica que a maioria (59\%) é casada ou possui união estável. Esses mesmos dados convergem também com a pesquisa CNT Confederação Nacional dos Transportes (2016). Nessa pesquisa, 68\% da população é casada.

Os dados da pesquisa também convergem com os resultados do GEM (2014) entre casados/união estável e solteiros. Esse percentual de casados denota uma maior responsabilidade do empresário em manter economicamente a sua família.

A formação acadêmica revela que o ensino médio completo (antigo colegial) destaca-se entre os taxistas, com 57,8\%. Em segundo lugar, está o ensino fundamental (antigamente conhecido como ginásio) presente em 22,4\% dos avaliados. O nível superior vem em seguida, com 15,6\%. Esses dados ratificam a Tabela 2, que mostra os valores completos. Esses mesmos dados convergem também com a pesquisa CNT Confederação Nacional dos Transportes (2016), ao identificar que 45,7\% possuem o ensino fundamental (antigo colegial). 
Tabela 2 - Nível de escolaridade entre os empreendedores taxistas identificados na pesquisa

\begin{tabular}{lcc}
\hline Nível & $\mathrm{N}$ & $\%$ \\
\hline Ensino Fundamental I (antigo Primário) & 6 & $4,1 \%$ \\
Ensino Fundamental II (antigo Ginásio) & 33 & $22,4 \%$ \\
Ensino Médio (antigo Colegial) & 85 & $57,8 \%$ \\
Superior & 23 & $15,6 \%$ \\
Pós-graduação & 0 & $0,0 \%$ \\
\hline
\end{tabular}

Fonte: Os autores

Foi perguntado se essas pessoas pensam em desistir de serem empreendedoras e os resultados estão na Tabela 4. Considerou-se avaliar essa variável para que, em próximas pesquisas, elas possam servir para comparações. Lembra-se que, por construção, elas não são medidas no instrumento utilizada. Dessa forma, são dados complementares à pesquisa.

Tabela 3 - Percepção de desistir, satisfação e atividade paralela à atividade de taxista

\begin{tabular}{lcc}
\hline Desistir & $\mathrm{N}$ & $\%$ \\
\hline Nunca & 28 & $19 \%$ \\
Raramente & 58 & $39,5 \%$ \\
Às vezes & 55 & $37,4 \%$ \\
Sempre & 6 & $4,1 \%$ \\
\hline Satisfação & & \\
\hline Satisfeito & 137 & $93,20 \%$ \\
Insatisfeito & 5 & $3,40 \%$ \\
Não respondido & 5 & $3,40 \%$ \\
\hline Atividade paralela & & $94,60 \%$ \\
\hline Não & 139 & $5,40 \%$ \\
Sim & 8 & \\
\hline
\end{tabular}

Fonte: Os autores

Observa-se que a possibilidade de desistir "raramente" é a maioria, com 39,5\%. A opção "nunca" soma 19\%, ou seja, 58,5\% não pensam em deixar a profissão. Esses dados aparentam reforçar a ideia da pesquisa CNT - Confederação Nacional dos 
Transportes (BRASIL - CNT, 2016). Mesmo sendo violenta a profissão, houve uma melhora na situação financeira dos taxistas quando comparado com a profissão anterior. Esses dados convergem para a expressão de satisfação dos taxistas em 93,20\%. De igual forma, a maioria dos taxistas não possui atividade paralela. O sustento de suas famílias vem do trabalho de táxi.

\subsection{Mensuração do nível de empreendedorismo dos taxistas e correlações}

Foi perguntado sobre o tempo em que o taxista está na cooperativa trabalhando nessa condição laboral. A média aproximada foi de sete anos, com um desvio de 0,54. O tempo mínimo na Cooperativa foi de um ano (quatro ocorrências), e o período máximo foi de 35 anos (uma ocorrência). Os dados da pesquisa CNT Confederação Nacional dos Transportes (BRASIL- CNT, 2016) registram que 28\% dos taxistas possuem até cinco anos em segundo lugar, e $28 \%$ dos taxistas de cinco a dez anos. O fato de os taxistas terem mais do que a média da pesquisa da CTN (BRASIL - CTN, 2016) pode estar relacionado a esses taxistas estarem vinculados a uma cooperativa.

Os resultados das médias de todas as dimensões da TEG são apresentados na Tabela 5. Para uma melhor comparação dos participantes desta pesquisa, as médias dos participantes foram comparadas com o ponto de corte sugerido pela autora do instrumento (CAIRD, 1991).

Tabela 4 - Resultado das dimensões do instrumento e média dos participantes

\begin{tabular}{lcccccc}
\hline & Corte & Média & DP & Mínimo & Máximo & P \\
\hline $\begin{array}{l}\text { Tendência de } \\
\text { assumir riscos }\end{array}$ & 8 & 6,30 & 1,59 & 2 & 10 & $<0,001$ \\
$\begin{array}{l}\text { Tendência criativa } \\
\text { Necessidade de }\end{array}$ & 8 & 6,22 & 1,81 & 1 & 10 & $<0,001$ \\
$\begin{array}{l}\text { realização } \\
\text { Tendência de }\end{array}$ & 9 & 6,41 & 1,94 & 2 & 11 & $<0,001$ \\
$\begin{array}{l}\text { autonomia } \\
\text { Tendência à }\end{array}$ & 4 & 2,92 & 1,18 & 0 & 6 & $<0,001$ \\
\hline
\end{tabular}


determinação

Fonte: Os autores

Observa-se que em nenhuma das dimensões do teste os taxistas avaliados atingiram a média para serem classificados como empreendedores. Os resultados demonstram que a média que mais se aproximou dos objetivos foi a da autonomia (com média 2,92), enquanto a mais distante foi a de necessidade de realização (com média 6,41). Ou seja, atitudes que remetem à confiança em si mesmo, otimismo, persistência e busca de um objetivo mostram-se distantes do perfil empreendedor taxista.

A aproximação dos valores em torno da média do constructo "autonomia" (com média 2,92) é próxima dos dados da pesquisa da CNT (BRASIL - CTN, 2016). Essa pesquisa identificou como vantagem na profissão a autonomia para definir o horário de trabalho.

É muito importante que o teste de hipóteses utilizado para comparar o resultado dos participantes, com os pontos de corte sugeridos pela autora do TEG revelou que todos os indicadores foram estatisticamente significativos.

Além disso, uma vez que a dimensão "tendência criativa" (com média 6,22) encontra-se abaixo da média (média 8), os autores mostram ainda mais preocupação, ao passo que essa tendência é importante em todos os aspectos do mercado de trabalho. Deficiências nesse constructo podem levar a conflitos desgastantes e podem ter na justiça a alternativa para a resolução. Sabe-se que esse fator pode auxiliar os taxistas a uma solução pacífica com essa nova concorrência no mercado de transporte de passageiros.

Os dados revelam que os taxistas são empreendedores por necessidade e não por oportunidade. Essa característica pode ser reforçada pelo fato de muitos deles serem casados e necessitarem manter economicamente seus lares. Atrelado a isso, características dos índices dos demais constructos reforçam a tese do empreendedorismo por necessidade e não por oportunidade.

$\mathrm{O}$ fato de os taxistas estudados serem cooperados aumenta a necessidade de capacidades empreendedora no sentido de serem os cooperados responsáveis pelo sucesso ou insucesso da organização. A pesquisa não teve como foco avaliar se esses taxistas estão "trajados" de cooperados ou não. No entanto, sem um perfil empreendedor, que uma cooperativa exige, corre-se o risco de serem manipulados por outros interesses.

Revista Eletrônica Gestão e Serviços v.7, n. , pp.1624-1648, Julho/Dezembro 2016.

ISSN Online: 2177-7284 e-mail: regs@metodista.br 
Tabela 5 - Correlação entre dimensões da TEG

\begin{tabular}{|c|c|c|c|c|c|c|}
\hline & TEG & $\begin{array}{l}\text { Tendência } \\
\text { de } \\
\text { assumir } \\
\text { riscos }\end{array}$ & $\begin{array}{c}\text { Tendência } \\
\text { criativa }\end{array}$ & $\begin{array}{l}\text { Necessidade } \\
\text { de } \\
\text { realização }\end{array}$ & $\begin{array}{l}\text { Tendência } \\
\text { de } \\
\text { autonomia }\end{array}$ & $\begin{array}{l}\text { Tendência à } \\
\text { determinação }\end{array}$ \\
\hline TEG & 1,00 & & & & & \\
\hline $\begin{array}{l}\text { Tendência de } \\
\text { assumir } \\
\text { riscos }\end{array}$ & 0,46 & 1,00 & & & & \\
\hline $\begin{array}{l}\text { Tendência } \\
\text { criativa }\end{array}$ & 0,56 & 0,03 & 1,00 & & & \\
\hline $\begin{array}{l}\text { Necessidade } \\
\text { de realização }\end{array}$ & 0,68 & 0,05 & 0,25 & 1,00 & & \\
\hline $\begin{array}{l}\text { Tendência de } \\
\text { autonomia }\end{array}$ & 0,50 & 0,18 & 0,21 & 0,19 & 1,00 & \\
\hline $\begin{array}{l}\text { Tendência à } \\
\text { determinação }\end{array}$ & 0,51 & 0,07 & $-0,02$ & 0,22 & 0,03 & 1,00 \\
\hline
\end{tabular}

Fonte: Os autores

\subsection{Correlação entre TEG e possíveis preditoras}

Um dos pontos de observação foi verificar qual o poder de predição de variáveis como escolaridade e sexo para o nível de empreendedorismo. Isso foi feito pela Análise da Variância, conforme explicitado na seção análise, é uma técnica que faz parte dos modelos lineares generalizados e é um caso particular de regressão (LINDSEY, 1997, p. 161). A literatura sugere sua utilização em casos onde o nível de medida da VD é intervalar e as VI são categóricas (KLEINMAN E HORTON, 2014, p. 93). 
Tabela 6 - Análise da variância entre variáveis sociodemográficas

\begin{tabular}{lccccc}
\hline & $\begin{array}{c}\text { Tipo III Soma } \\
\text { dos Quadrados }\end{array}$ & $\mathrm{gl}$ & $\begin{array}{c}\text { Quadrado } \\
\text { Médio }\end{array}$ & $\mathrm{Z}$ & $\mathrm{P}$ \\
\hline Sexo & 14,26 & 146 & 0,10 & 1,09 & 0,37 \\
Estado civil & 74,04 & 146 & 0,56 & 1,13 & 0,32 \\
Escolaridade & 76,71 & 146 & 0,98 & 2,21 & $<0,01$ \\
Carga horária & 97,02 & 146 & 0,71 & 1,08 & 0,38 \\
Atividade paralela & 7,56 & 146 & 0,05 & 0,87 & 0,63 \\
Vontade de desistir & 96,65 & 146 & 0,79 & 1,24 & 0,22 \\
Tempo de trabalho (em & & & & & \\
anos) & 6220,22 & 146 & 61,68 & 1,58 & 0,06 \\
\hline
\end{tabular}

Fonte: Os autores

Tabela 7 - Post hoc Bonferroni para TGE dado Escolaridade (Referência pelo ensino Superior)

\begin{tabular}{|c|c|c|c|c|c|c|}
\hline \multirow{2}{*}{\multicolumn{2}{|c|}{ Escolaridade }} & \multirow{3}{*}{$\begin{array}{l}\begin{array}{l}\text { Diferença } \\
\text { média }\end{array} \\
-2,09\end{array}$} & \multirow{3}{*}{$\begin{array}{c}\begin{array}{c}\text { Erro } \\
\text { Padrão }\end{array} \\
1,89\end{array}$} & \multirow{3}{*}{$\begin{array}{l}\mathrm{P} \\
1,00\end{array}$} & \multicolumn{2}{|c|}{ Intervalo de Confiança 95\% } \\
\hline & & & & & \multirow{2}{*}{$\begin{array}{r}\text { Limite inferior } \\
-7,16\end{array}$} & \multirow{2}{*}{$\begin{array}{r}\text { Limite superior } \\
2,97\end{array}$} \\
\hline Primário & Ginásio & & & & & \\
\hline & Colegial & $-4,20$ & 1,80 & 0,13 & $-9,02$ & 0,62 \\
\hline & Superior & $-7,16$ & 1,96 & $<0,01$ & $-12,39$ & $-1,93$ \\
\hline \multirow[t]{3}{*}{ Ginásio } & Primário & 2,09 & 1,89 & 1,00 & $-2,97$ & 7,16 \\
\hline & Colegial & $-2,11$ & 0,87 & 0,10 & $-4,45$ & 0,23 \\
\hline & Superior & $-5,07$ & 1,16 & $<0,01$ & $-8,17$ & $-1,97$ \\
\hline \multirow[t]{3}{*}{ Colegial } & Primário & 4,20 & 1,80 & 0,13 & $-0,62$ & 9,02 \\
\hline & Ginásio & 2,11 & 0,87 & 0,10 & $-0,23$ & 4,45 \\
\hline & Superior & $-2,96$ & 1,00 & 0,02 & $-5,64$ & $-0,27$ \\
\hline \multirow[t]{3}{*}{ Superior } & Primário & 7,16 & 1,96 & $<0,01$ & 1,93 & 12,39 \\
\hline & Ginásio & 5,07 & 1,16 & 0,00 & 1,97 & 8,17 \\
\hline & Colegial & 2,96 & 1,00 & 0,02 & 0,27 & 5,64 \\
\hline
\end{tabular}

Fonte: Os autores 
Os resultados da Tabela 7 mostram que a relação entre o nível superior e os outros níveis são todos diferentes. Ou seja, cada grau de escolaridade contribui diferentemente para a tendência empreendedora. Como o teste não mostra onde esse grau é maior/menor, apresenta-se um post-hoc secundário ou hierárquico na Tabela 7.

Observa-se que os níveis de ensino diferenciam-se entre si. O nível superior destaca-se em todos os outros níveis. Dessa forma, os anos de estudo têm interferência positiva no empreendedorismo.

Resultado algo contraintuitivo foi a constatação de que pessoas empregadas há mais tempo diminuem sua tendência ao empreendedorismo. Provavelmente, é importante pensar sobre estratégias de qualidade de vida no trabalho que possam reverter esse quadro e potencializar o perfil de empreendedorismo por parte dos taxistas.

É importante lembrar que uma correlação não significa causalidade e que essa situação de inversão proporcional pode ter sido causada por variáveis estranhas à avaliação e que não foram medidas ou controladas (BUSSAB E MORETIN, 2010).

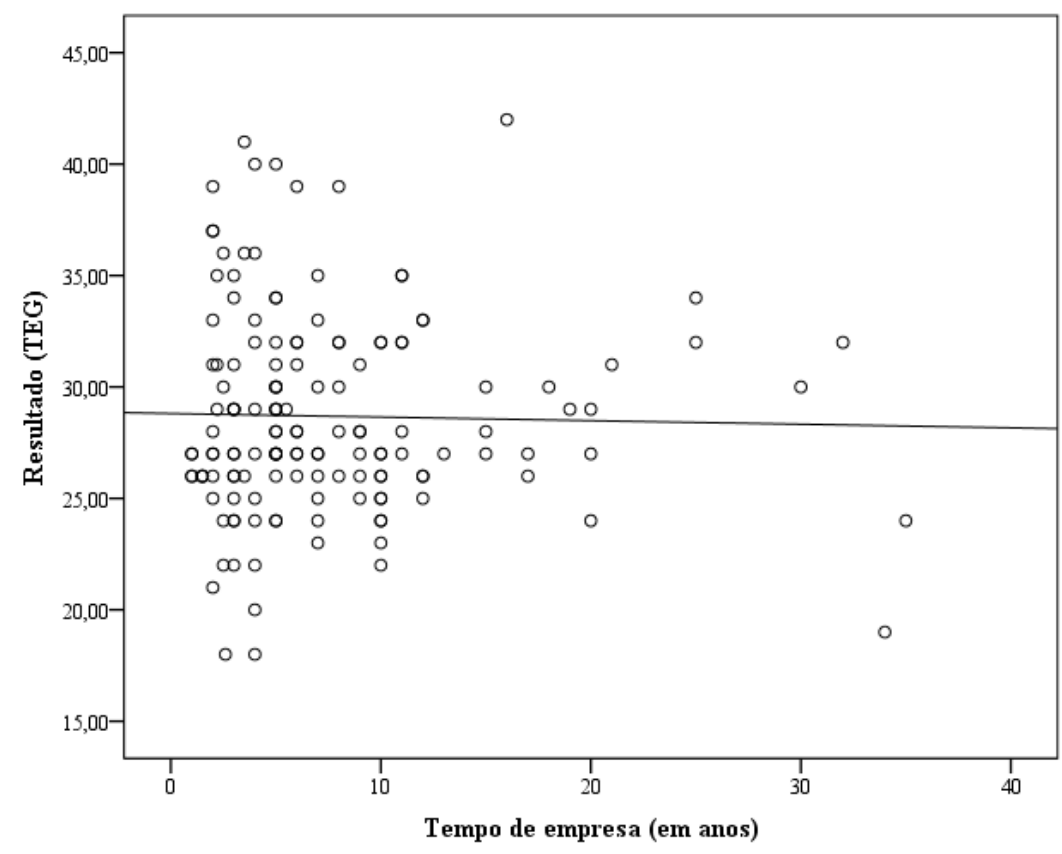

Gráfico 1. Correlação entre TEG dado Tempo de empresa Fonte: Os autores

\section{CONSIDERAÇÕES FINAIS}

O objetivo da pesquisa foi identificar o perfil empreendedor dos taxistas. Foram apresentados os dados sociodemográficos e a avaliação do empreendedorismo pelo 
modelo de Caird (1991).

A população avaliada foi formada majoritariamente por homens casados. O nível de escolaridade que mais apareceu foi o Ensino Médio (antigo colegial). Os resultados da pesquisa indicaram que nenhum dos cinco constructos propostos por Caird (1991) sobre o empreendedorismo foram atingidos pela população estudada.

Analisando a tendência empreendedora de forma geral e comparativa à solicitada por Ferreira e Aranha (2008), observa-se que os taxistas avaliados apresentaram uma baixa tendência empreendedora em todas as dimensões avaliadas pelo instrumento, mesmo considerando o desvio padrão presente neste resultado.

Dessa forma, os dados indicam pela rejeição de H1 - que afirmava: H1 - Os taxistas possuem grau de empreendedorismo acima da média.

A correlação entre o nível da TEG e a tentativa de desistir (ou não da profissão) não mostrou diferenças estatísticas significantes. Ou seja, a percepção de pensar "sempre desistir" com a percepção de "nunca" desistir não se associa à TEG.

Com os resultados anteriores, analisou-se a correlação entre a "satisfação e insatisfação" (em relação a participar da cooperativa) com os níveis de TEG. Mais uma vez, os resultados não mostraram diferenças estatísticas significantes.

Outra forma de buscar conhecer mais sobre os baixos níveis de TEG foi o estudo do grau de escolaridade. Nesse quesito, observou-se que quanto mais estudado é o taxista, tanto maior é o seu nível de TEG. Dessa forma, reforçam-se a ideia de capacitação nas mais diversas formas aos taxistas, mostrando o benefício da sua atividade profissional.

Portanto, conclui-se pela rejeição de $\mathrm{H} 2$ - quanto maior o nível de educação formal do taxista tanto maior é o seu grau de empreendedorismo.

A correlação entre a TEG e os tempos de trabalho na cooperativa mostrou-se contraintuitiva. Ou seja, quanto mais o taxista trabalha, tanto menor é o seu índice de empreendedorismo. Provável ser uma busca por qualidade de vida ou até mesmo de necessidades básicas já suprimidas.

Logo, conclui-se pela rejeição de H3 - quanto maior o tempo na profissão tanto maior é o grau do empreendedorismo.

A última correlação identificada no estudo foi a carga horária diária com os níveis de empreendedorismo. Nesse quesito, identificou-se que quanto mais trabalha diariamente, tanto menor é o nível de TEG. O constructo "tendência à determinação" 
mostrou-se inversamente proporcional aos demais. Nesse item, quanto mais horas de trabalho diária, tanto menor é a tendência à determinação. Nesse caso, o taxista perde, entre outros, a percepção das oportunidades do negócio em si.

Os achados da pesquisa, considerando todos os baixos indicadores, parecem direcionar a dificuldades de identidade apontadas por Veloso, Oliveira Filho e Medeiros (2009). As médias sugerem ausência de determinação, criatividade, autonomia, exposição ao risco e determinação (construtos analisados) para o serviço de táxi.

Tal resultado leva a sugerir que o taxista não deseja nem se prepara para tal, confirmando a ideia de Nóbrega (2008) sobre "emprego alternativo" para a "sobrevivência".

Ampliar a capacitação dos taxistas poderia reverter esse fluxo passando para um sujeito ativo modificando/alterando o seu meio com autonomia. Destaca-se mais cursos de atualização e reforço na formação por parte dos órgãos que assistem esses profissionais. Sugere-se curso de extensão na área de Marketing, especialmente pessoal, Planejamento Estratégico, Gestão de Relacionamento, Gestão Financeira, Tecnologia da Informação e também terapias grupais em Psicologia. Todos esses temas visam apoiar/acolher esses profissionais e atender a demandas de formação que hoje se apresentam. Certamente, os profissionais de Administração e Psicologia podem contribuir e muito com essa formação constante.

Este trabalho buscou contribuir para o desenvolvimento científico e social dos taxistas. $\mathrm{O}$ estudo pode ser considerado um avanço tanto aos taxistas como ao estudo do empreendedorismo, sendo uma fonte para consultas, aplicações e estímulos para novas pesquisas.

O trabalho apresenta limitações. Uma delas é o número que não representa a totalidade de taxistas cooperados da cidade em estudo, e muito menos uma generalização para as outras cooperativas da cidade.

Ademais, os autores entendem que estudos de maior profundidade precisam ser feitos. Entendem, também, que uma avaliação psicométrica do modelo de Caird (1991) venha a ser propício.

\section{REFERÊNCIAS}

ALMEIDA, Joana Gomes de Almeida, SANTOS, Eduardo J. R., ALBUQUERQUE, Cristina Pinto, FERREIRA, Joaquim Armando. PLURAL, Revista do Programa de Pós-Graduação em Sociologia da USP. São Paulo, v. 20.1, 2013, p. 31-56. 
ARAUJO, A. C. C.; DANTAS, T. F. Tendência empreendedora dos estudantes de Engenharia da UFG através do modelo de Durham. Qualit@s (UEPB), v. 8, p. 1-10, 2009.

BARROS, A. A.; PEREIRA, C. M. A. Empreendedorismo e crescimento econômico: uma análise empírica. RAC. Revista de Administração Contemporânea, v. 12, p. 5064, 2008.

BARROS, Daniel Ferreira; SCARANCE, Laís Morais Nobre; NOGUCHI, Michele Ayumi Saito; CASSIMIRO, Tauane Angélica da Silva, NACIF, Marcia. Perfil nutricional de taxistas da zona central de São Paulo. EFDeportes.com: Revista Digital. Buenos Aires, Ano 18, nº 184, setembro de 2013.

BENTO, Flávio, TRINDADE, André Fernando dos Reis, LIMA, Rosimeire Midori Suzuki Rosa, GARCIA, Regis. A Terceirização de Atividades e a Utilização de Cooperativas de Trabalho pelas Empresas: Entre a Legalidade e a Ilegalidade.

UNOPAR Cient., Ciênc. Juríd. Empres. Londrina, v. 14, n. 2, p. 173-180, set. 2013.

BRAGA, J. C. M.; ZILLE, L. P. Estresse no Trabalho: estudo com taxistas na cidade de Belo Horizonte. CONTEXTUS - Revista Contemporânea de Economia e Gestão, v. 13, p. 34-50, 2015.

BRANCHER, I. B.; OLIVEIRA, E. M.; RONCON, A. Comportamento empreendedor: estudo bibliométrico da produção nacional e a influência de referencial teórico internacional. Internext - Revista Eletrônica de Negócios Internacionais da ESPM, São Paulo, v. 7, n. 1, p. 166-193, jan./jun.

BRASIL - DENATRAN - Portaria 168/2004 - Estabelece Normas e Procedimentos para a formação de condutores de veículos automotores e elétricos. Brasília, 2004.

BRASIL - Lei 12.587 - Institui as diretrizes da Política Nacional de Mobilidade Urbana. Brasília, 2012.

BRASIL - Lei $\mathbf{n}^{\mathbf{0}} \mathbf{. 5 . 7 6 4 / 7 1}$ - Define a Política Nacional de Cooperativismo, institui o regime jurídico das sociedades cooperativas, e dá outras providências.

CAIRD, S. The enterprising tendency of occupational groups. International Small Business Journal, 9(4), 75-81, 1991.

CARDOSO, Univaldo Coelho. Associacão. Brasília: Sebrae, 2014.

CARREIRO, D. L.; COUTINHO, L. T. M.; COUTINHO, W. L. M. Tendência empreendedora do acadêmico de Educação Física. Revista Mineira de Educação Física (UFV), v. Ed. Esp, p. 115-124, 2010.

CARREIRO, D. L.; COUTINHO, L. T. M.; DE MELO JÚNIOR, R. F. C.;

COUTINHO, W. L. M. Comparação da tendência empreendedora entre acadêmicos de 
Educação Física e Fisioterapia. Lecturas Educación Física y Deportes (Buenos Aires), v. 15, 2010.

CASTELLI, Geraldo. Gestão Hoteleira. São Paulo/SP: Saraiva, 2006.

CHANFFIN, D. B.; ANDERSSON, G. B. J.; MARTIN, B. J. Biomecânica

Ocupacional. Belo Horizonte: Ergo, 2001.

COOPER, Donald R.; SCHINDLER, Pamela S. Métodos de pesquisa em administração, 7. ed. Porto Alegre: Bookman, 2003.

DELFINO, Islania A. L.; LAND, Aline Grams; SILVA, Walmir Rufino da. A Relação entre Valores Pessoais e Organizacionais Comparados aos Princípios do Cooperativismo. Gerais: Revista Interinstitucional de Psicologia, v. 3, p. 67-80, 2010.

DEMO, Pedro. Metodologia Científica em Ciências Sociais. São Paulo: Atlas, 1985.

DIAS, Flávio Augusto de Oliveira Passos. Serviços de Táxi. Dissertação de mestrado do departamento de engenharia civil e ambiental, 2007. Brasília. Disponível em: $</ /$ bdtd.bce.unb.br $>$. Acesso em: 9 abr. 2015.

DOLABELA, F. O segredo de Luísa. São Paulo: Picture, 2006.

ESTHER, Angelo Brigato. Empreendedorismo: Contexto, Concepções e Reflexões. V III-ENEO - Encontro de Estudos Organizacionais da ANPAD. Rio Grande do Sul Gramado, 2014.

FERREIRA, R. C.; ARANHA, E. A. Análise do perfil empreendedor de graduados em Engenharia de Produção Mecânica. Universidade Federal de Itajubá. Minas Gerais: UNIFEII, 2008.

FLORES, Álvaro dal Molin A.; SANTOS, L. F. O perfil empreendedor de acadêmicos em Administração em uma cidade do sul do país. Revista Acadêmica São Marcos, v. 4, p. 71-88, 2014.

GAIÃO, B. F. S.; LIRA, W. S.; SILVA, T. A.; QUEIROZ, C. T. A. P. Diagnóstico da tendência empreendedora através do modelo de Durham: um estudo de caso no setor educacional. Qualit@s (UEPB), v. 8, p. 338, 2009

GANY, F. M. et al. "Every disease... man can get can start in this cab": Focus Groups to Identify South Asian Taxi Drivers' Knowledge, Attitudes and Beliefs About cardiovascular Disease and Its Risks. Journal Immigrant Minority Health. New York, 2012.

GAWLAK, A.; RATZKE, F. A. Cooperativismo: Filosofia de vida para um mundo melhor. Curitiba: Sescoop/Pr-Ocepar, 2001.

GEM-Global Entrepreneurship Research Association - Empreendedorismo no Brasil

Revista Eletrônica Gestão e Serviços v.7, n. , pp.1624-1648, Julho/Dezembro 2016.

ISSN Online: 2177-7284 e-mail: $\underline{\text { regs@ @metodista.br }}$ 
relatório executivo-2014.

GUARDABASSIO, E. V.; AMORIM, W.; PEREIRA, R. S. Geração de Trabalho e Renda por meio do Cooperativismo. In: XXXVII Encontro da ANPAD - EnANPAD 2013. Rio de Janeiro, 2013.

GUERBALI, S. M.; OLIVEIRA, Luciel; SILVEIRA. Gestão de Projetos na Área de Telecomunicações: Características Empreendedoras dos Gerentes de Projetos. In: ALTEC, 2013, Porto. XV Congresso Latino-Iberoamericano de Gestão de Tecnologia, 2013.

IIZUKA, Edson Sadao; MORAES, Gustavo Hermínio Salati Marcos de. Potencial e Perfil Empreendedor do Estudante de Administração e o Ambiente Universitário: Investigação em três IES de São Paulo. In: XVII SEMEAD 2014 - FEA/USP, 2014, São Paulo. São Paulo: FEA/USP, 2014.

KLEINMAN, K., HORTON, N. J. SAS and R: Data Management, Statistical Analysis, and Graphics (second edition). Boca Raton: CRC Press, 2014.

LEAL, A. D. C.; LIRA, W. S. Diagnóstico da Tendência Empreendedora do Corpo Docente de uma Instituição Pública de Ensino Superior. In: VIII SEGeT Simpósio de Excelência em Gestão e Tecnologia 2011, 2011, Rio de Janeiro, SEGET 2011, 2011.

LINDSEY, J. K. Applying Generalized Linear Models. New York: Springer, 1997.

LINS, H. N. Cooperativas de trabalhadores: opção frente à crise do emprego ou aspecto da crescente precariedade do trabalho? Nova Economia (UFMG). Belo Horizonte, v. 11 , n. 1, p. 39-75, 2001.

LIRA, Helio de Lucena; LIRA, W. S.; MORAIS, C. R. S. Vocação Empreendedora dos Estudantes de Engenharia de Materiais da Universidade Federal de Campina GrandePB. In: XXXIII Congresso Brasileiro de Ensino de Engenharia, 2005, Rom., p. 0109, 2005.

LOPES, E. J.; TOIMIL, L. S. F. R. Hábitos alimentares e estado nutricional de trabalhadores noturnos de uma indústria metalúrgica da cidade de Guarulhos. VII Jornada de iniciação científica em nutrição. São Paulo, 2011.

McCLELLAND, D. Business Drive and National Achievement. Harvard Business Review, jul./aug., 1962.

MELGAREJO-MOLINA, Z., VERA-COLINA, M. A., MORA-RIAPIRA, E. H. (2012). La supervivencia de las Cooperativas de Trabajo Asociado en Colombia: una aproximación teórica. Innovar, 22(45), 5-16.

MIRANDA, M.; TINÔCO, Dinah dos Santos. A Terceirização dos Serviços Públicos através de Cooperativas de Trabalho: O Caso de Itajá-RN. In: XXVI ENANPAD, 2002 Associação Nacional dos ANPAD Programas de Pós-Graduação em Administração Salvador/Bahia, 2002, p. 01-15. 
NIVEIROS, Sofia Inês; ALMEIDA, Eliane Marques de, ARENHARDT, Ramon Luiz. Investigação e análise do perfil empreendedor dos alunos do curso de Ciências Contábeis da UFMT. $2^{\circ}$ Congresso de Controladoria e Finanças \& Iniciação Científica em Contabilidade. Universidade Federal de Santa Catarina - UFSC Florianópolis-SC., 2008.

NOBRE, Nélia. (Des)emprego e empreendedorismo: repensar as políticas públicas, Configurações [On-line], v. 10, 2012, posto on-line no dia 17 fevereiro 2014, consultado em 21 agosto 2015. URL: http://configuracoes.revues.org/1410.

NÓBREGA, Ricardo. Trabalhadores em Trânsito: Um Estudo sobre os Taxistas do Rio de Janeiro. Cadernos de Sociologia e Política (On-line), v. 1, p. 81-98, 2008. OCB - Organização das Cooperativas Brasileiras. Institucional no site http://www.ocb.org.br/site/ramos/transporte_conceito.asp acessado em 27/8/2015.

PANTZIER, Rolf Dieter. Empreendedorismo e formação de Administradores: uma análise do curso de Administração da UFRB - Dissertação de Mestrado em Administração da Universidade Regional de Blumenau, 1999.

PELOGGIA, Lucinei Rossi. Perfil empreendedor do engenheiro na produção industrial: o caso de duas empresas aeronáuticas no Brasil. Monografia (Especialização MBA - Gerência da Produção e Tecnologia) - Universidade de Taubaté. Taubaté, 2001, 90s.

PORTER, Michael E. Estratégia Competitiva - Técnicas para análise de indústrias e da concorrência, 18. ed. São Paulo-SP: Campus, 1986.

ROSA, Catarina; ROSA, Cátia; BERTO, Mariana; DUARTE, Vera. Inteligência emocional e capacidade empreendedora dos estudantes de ensino superior.

International Journal of Developmental and Educational Psychology, n. 1, v. 3, 2011. ISSN: 0214-9877, p. 631-640.

ROSA, Gabriel Luis. Os taxistas de Florianópolis $\mathrm{S} / \mathrm{C}$ e o ambiente noturno urbano da cidade. Revista de Ciências Humanas. Florianópolis, v. 46, n. 2, p. 535-543, out. 2012.

RUSSO, Rosária de Fátima SeggerMacri; SBRAGIA, Roberto. Tendência empreendedora do gerente: uma análise de sua relevância para o sucesso de projetos inovadores. Gestão \& Produção (UFSCAR. Impresso), v. 14, p. 581-593, 2007.

SALIM, C. et al. Administração empreendedora: teoria e prática usando o estudo de casos. Rio de Janeiro: Elsevier, 2004.

SÃO PAULO - PREFEITURA - LEI 16.279/2015. Dispõe sobre a proibição do uso de carros particulares cadastrados em aplicativos para o transporte remunerado individual de pessoas no Município de São Paulo, e dá outras providências. Disponível em: http://cmspbdoc.inf.br/iah/fulltext/leis/L16279.pdf acessadodia 28/10/2015 às 17:19.

SERAFIM, Mauricio C. e FEUERSCHUTTE, Simone Ghisi. Movido pelo 
transcendente: a religiosidade como estímulo ao "espírito empreendedor". Cad. EBAPE.BR [on-line], 2015, v. 13, n. 1, p. 165-182. Epub Mar-2015. ISSN 1679-3951.

SILVA NETTO, Gilberto da Mota. "Confiar desconfiando": vulnerabilidade, risco e produção de segurança na atividade dos taxistas da cidade do Recife. Dissertação em sociologia da UFPE, 2011.

SILVA, T. N.; GIESTA, Lílian Caporlígua. Cooperativas de trabalho, alternativa ao desemprego ou fachada: a percepção de alguns de seus stakeholders. In: XXXI Encontro da ANPAD - EnANPAD, 2007. Rio de Janeiro, 2007.

SIMÃO, Bácima Eliana Alves. Perfil empreendedor dos alunos concluintes do curso de Administração de uma Instituição de Ensino Superior: contribuições para o aprimoramento do Projeto Pedagógico do Curso. Dissertação de Mestrado em Educação da UNOESTE, 2012.

SCHMIDT, Derli; PERIUS, Vergílio. Cooperativismo - cooperativa. In: CATTANI, Antonio David (Org.). A outra economia. Porto Alegre: Veraz Editores, 2003.

SOUZA, R. S.; SILVEIRA, Amélia; NASCIMENTO, Sabrina do; SANTO, M. O. E. Vendedores ambulantes e o Modelo de CAIRD (1991): Tendência Empreendedora Geral (TEG). In: Encontro de Estudos sobre Empreendedorismo e Gestão de Pequenas Empresas, 2014. Goiânia, GO. Anais do VIII EGEPE. São Paulo, SP: ANEGEPE, 2014, v. 1, p. 1-16.

STEFANO, S. R.; ZAMPIER, M. A.; GRZESZCZESZYN, G. Cooperativas: características, gestão e relevância sócio-econômica para o Brasil. In: IX SEMEAD Seminários em Administração FEA-USP-2006. São Paulo, 2006.

TELLES, R. Considerações sobre tipificação da investigação Científica e Pesquisa Qualitativa. Revista Álvares Penteado, São Paulo, 2001.

UBER. Site institucional em https://www.uber.com/ acessado em 01/11/2015 às 14:09.

VEDOIN, A. M. R.; GARCIA, O. M. C. Tendência empreendedora: perfil dos alunos do curso de Arquivologia da Universidade Federal de Santa Maria. In: XIII SEMEAD, 2010, São Paulo. Anais... São Paulo: FEA/USP, 2010.

VELOSO, Thelma Maria Grisi; OLIVEIRA FILHO, Pedro de; MEDEIROS, Carolina Silva de, ARAUJO, Audizélia dos Santos. A identidade em discursos de taxistas. Psicol. Soc. [on-line], 2009, v. 21, n. 1, p. 118-127. ISSN 1807-0310. VIEIRA, Marcelo Carvalho. Hipertensão arterial e características ocupacionais em motoristas de táxi do Município do Rio de Janeiro. Dissertação apresentada à Escola Nacional de Saúde Pública Sergio Arouca para obtenção do grau de Mestre. Rio de Janeiro; s.n.; 2009. 